\title{
Analisa Pembebanan pada Motor Brushless DC (BLDC)
}

\author{
${ }^{1}$ Yunus Chandra Wibowo 2 Slamet Riyadi \\ Teknik Elektro, Fakultas Teknik, Universitas Katolik Soegijapranata \\ Semarang, Indonesia \\ yunuschandrawibowo@yahoo.com, sriyadi7167@gmail.com
}

\begin{abstract}
Abstrak
Aplikasi dari energi terbarukan semakin banyak dikembangkan salah satunya pada bidang transportasi elektrik. Sudah banyak alat transportasi yang telah menggunakan motor modern sebagai tenaga penggeraknya, diantaranya adalah motor switch reluctance dan brushless DC (direct current). Motor BLDC atau motor brushless dc sendiri memiliki kelebihan efisiensi tinggi dan rugi-rugi mekanik yang rendah karena tidak menggunakan sikat (brush) seperti motor dc konvensional. Inverter tiga fasa diperoleh untuk dapat mengalirkan arus/tegangan bolak-balik yang menghasilkan elektromagnetik kutub utara ataupun selatan. Pada makalah ini dilakukan kajian dengan pembebanan motor BLDC, Pembebanan direalisasikan dengan mengggunakan generator DC yang dibebani dengan variable resistor. Pengujian laboratorium dilakukan untuk mendukung hasil analisis.
\end{abstract}

Kata kunci : transportasi elektrik, efisiensi tinggi, brushless dc, inverter tiga fasa, pembebanan

\section{Pendahuluan}

Akibat penggunaan kendaraan konvensional dan juga industri yang berbahan bakar fosil berdampak pada lingkungan, emisi gas buang yang dihasilkan oleh pembakaran motor bakar merupakan masalah utama dari timbulnya kerusakan ekosistem. Masalah ini semakin memburuk dengan semakin meningkatnya jumlah penggunaan kendaraan berbahan bakar fosil. Untuk dapat menanggulangi masalah ini dikembangkanlah kendaraan listrik dengan berbagai macam motor listrik. Pada awalnya kendaraan listrik menggunakan motor DC karena mempunyai karakteristik torka awalnya yang kuat sehingga dapat menarik beban yang berat seperti kendaraan listrik. Tetapi motor DC memiliki salah satu kelemahan yaitu adanya sikat (brush) dan komutator.

Dari kelemahan motor DC tersebut maka motor ini mulai ditinggalkan. Seiring perkembangan teknologi kendaraan listrik mulai menerapkan penggunaan motor modern. Di antaranya motor modern yang digunakan yaitu motor BLDC. Penggunaan motor BLDC untuk aplikasi kendaraan listrik, industri dan aplikasi lainnya banyak digunakan karena motor ini memiliki karakteristik yang sama dengan motor DC tetapi tidak menggunakan sikat untuk beroperasi sehingga biaya perawatan yang dibutuhkan rendah dan lebih praktis, kecepatan yang lebih baik dibandingkan karakteristik torsi dan respons dinamis yang lebih besar.

Secara konstruksi, pada umumnya motor BLDC terdiri dari rotor magnet permanen dan stator berupa belitan kawat email. Di dalam motor juga dilengkapi dengan sensor hall effect untuk mendeteksi posisi magnet pada rotor. Rangkaian daya yang digunakan untuk pensaklaran pada motor BLDC berupa inverter tiga fasa untuk dapat mengalirkan arus/tegangan bolak-balik AC (alternating current) yang menghasilkan elektromagnetik kutub utara maupun selatan. Dan digunakan juga mikrokontroller dengan suplai dari catu daya. Pada makalah ini kontruksi motor BLDC terdiri dari delapan kutub rotor dan duabelas kutub stator. Dalam implementasi ini dilakukan kajian dengan pembebanan pada motor BLDC, Pembebanan direalisasikan dengan mengggunakan generator DC yang diaplikasikan sebagai roda pada system penggerak mekanik yang dibebani dengan tiga variasi resistor pada kondisi motoring untuk mendapatkan respon motor.

\section{Metodologi Penelitian}

Pada penelitian ini digunakan motor brushless dc (BLDC) yang digerakan oleh rangkaian daya berupa inverter tiga fasa dengan tiga variasi beban resistif pada kondisi motoring.

\subsection{Motor Brushless DC}

Motor BLDC merupakan jenis motor listrik synchronous. Pada umumnya motor BLDC bekerja dengan gaya tarik antara dua magnet dengan kutub yang sama. Secara kontruksi Motor BLDC terdiri dari rotor yang berupa magnet permanen sehingga kutubnya tetap sedangkan stator berupa belitan kawat email sehingga kutub magnet tersebut dapat berubah tergantung polaritas arus belitan stator yang diberikan. Pada motor BLDC ini memiliki kontruksi berupa duabelas belitan stator dan delapan kutub magnet permanen pada rotornya. 
Untuk dapat mengatur putaran pada motor BLDC, diperlukan informasi untuk mengetahui letak rotor. Untuk itu diperlukan sensor pendeteksi posisi rotor yaitu hall effect sensor yang merupakan sensor dengan kemampuan mendeteksi letak magnet.

Jika dijabarkan hall effect sensor memberikan keluaran "0" saat kutub magnet selatan (S) dekat dengan sensor dan akan berlogika "1" saat mendeteksi keberadaan kutub magnet utara $(\mathrm{N})$. Tiga buah hall effect sensor ditempatkan pada posisi sebagai berikut : $\mathrm{H} 1$ pada posisi $\theta=330^{\circ}, \mathrm{H} 2$ pada posisi $\theta=90^{\circ}$, dan $\mathrm{H} 3$ pada posisi $\theta=210^{\circ}$ terhadap stator.

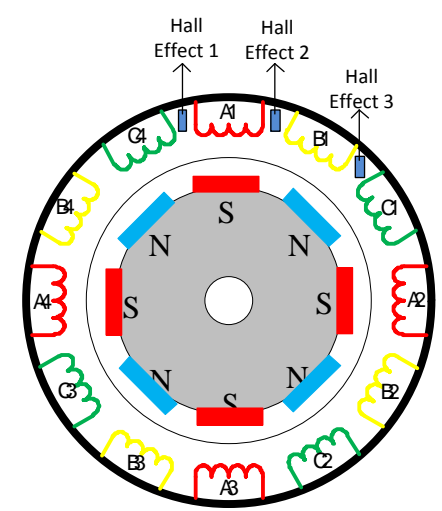

Gambar 1 kontruksi motor brushless dc

Persamaan torsi pada motor BLDC disajikan pada persamaan berikut ini :

$$
T=K r m s . \phi . I(N m)
$$

$\mathrm{R}$

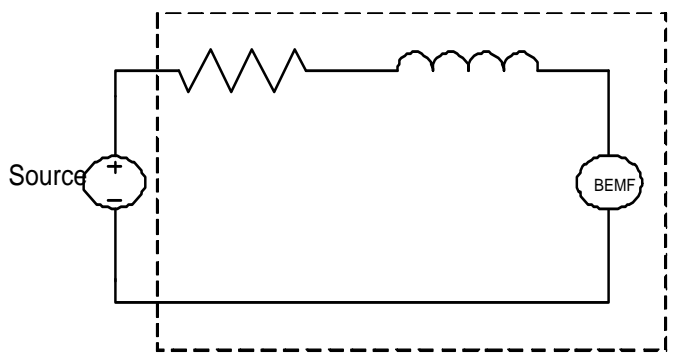

Gambar 2 rangkaian ekuivalen stator motor bldc

Besarnya EMF balik dapat berpengaruh pada medan magnet yang dihasilkan rotor (B), kecepatan sudut putaran motor $(\omega)$, dan banyaknya lilitan pada belitan stator $(\mathrm{N})$ sehingga besarnya EMF balik dapat dihitung melalui persamaan berikut ini:

$$
B E M F=\text { B.N.1.r. } \omega
$$

\section{Topologi Inverter Tiga Fasa}

Agar dapat menghasilkan medan magnet pada stator dibutuhkan suatu alat yang dapat mengalirkan arus bolak-balik untuk menghasilkan elektromagnetik kutub utara ataupun selatan. Karena stator pada motor BLDC terdiri dari tiga belitan yang disusun bintang, Oleh karena itu untuk menggerakan motor BLDC diperlukan inverter tiga fasa.

Inverter itu sendiri merupakan rangkaian elektronika daya yang berfungsi mengubah arus dan tegangan searah (DC) menjadi arus dan tegangan bolak-balik (AC). Inverter tiga fasa sendiri pada dasarnya memiliki kesamaan dengan inverter satu fasa. Akan tetapi outputnya berupa tiga gelombang AC yang saling bergeser $120^{\circ}$ yang satu dengan yang lainya.

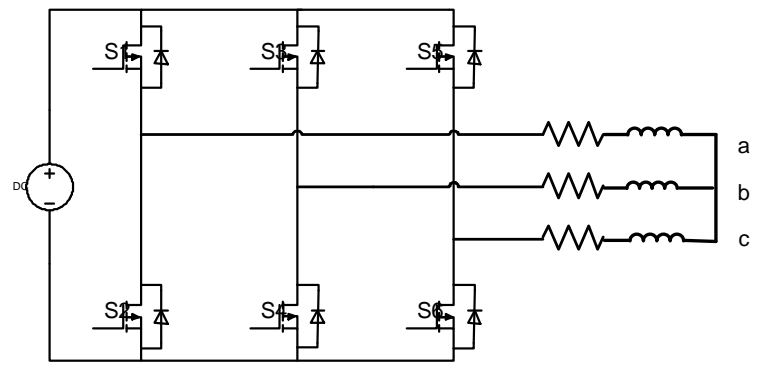

Gambar 3 rangkaian inverter tiga fasa

Sebuah inverter tiga fasa terhubung dengan motor. Pengendalian pada bagian inverter ini seperti motor sinkron yang memiliki persamaan putaran mesin yang harus diimplementasikan dalam kontrol inverter.

Suatu inverter tiga lengan yang mempunyai enam buah saklar elektronik yang dapat dikendalikan dalam kondisi on dan off-nya. Untuk memperoleh enam macam konfigurasi switching dari inverter tersebut maka masing-masing pasang saklar pada tiap lengan akan dikendalikan sendirisendiri seperti tampak pada Tabel 1

Tabel 1 konfigurasi pensaklaran inverter tiga fasa

\begin{tabular}{|c|c|c|c|c|c|c|c|c|}
\hline S6 & S5 & S4 & S3 & S2 & S1 & Van & Vbn & Vcn \\
\hline 1 & 0 & 0 & 1 & 0 & 0 & Vdc & - Vdc & 0 \\
\hline 1 & 0 & 0 & 0 & 0 & 1 & Vdc & 0 & - Vdc \\
\hline 0 & 0 & 1 & 0 & 0 & 1 & Vdc & - Vdc & 0 \\
\hline 0 & 1 & 1 & 0 & 0 & 0 & 0 & - Vdc & Vdc \\
\hline 0 & 1 & 0 & 0 & 1 & 0 & $-V d c$ & 0 & Vdc \\
\hline 0 & 0 & 0 & 1 & 1 & 0 & $-V d c$ & Vdc & 0 \\
\hline
\end{tabular}




\section{Mode Operasi Pensaklaran}

Pada gambar 4 dijelaskan bahwa saklar S6 dan S3 dalam kondisi menyala, arus mengalir dari fase A pada belitan motor ketika saklar dimatikan, kelebihan energi akan dibuang melalui dioda D1 dan D2. Dan akan menghasilkan keluaran 0 dan 1 untuk selanjutnya disalurkan pada mikrokontroller. Gambar 5, gambar 6, gambar 7, gambar 8 dan gambar 9 menunjukkan enam mode operasi yang terus berulang dengan saklar yang saling bergantian dalam kondisi menyala dan mati.

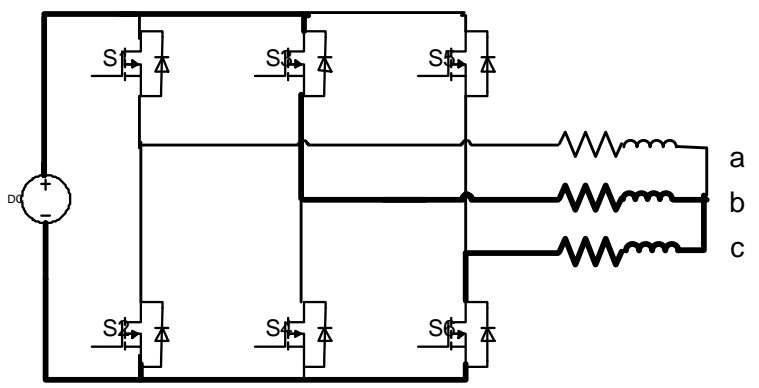

Gambar 4 mode operasi pensaklaran 1 ( B - C )

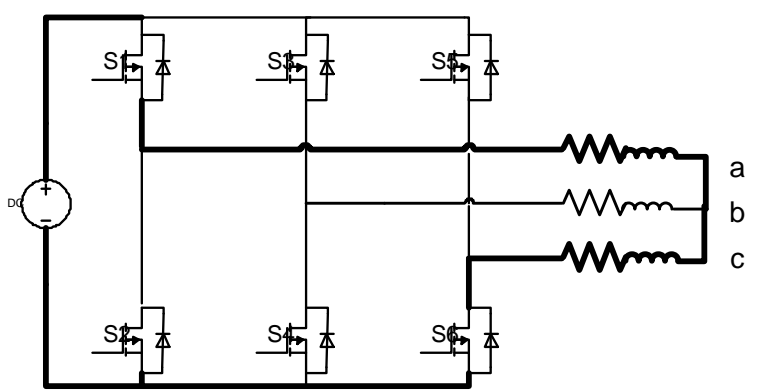

Gambar 5 mode operasi pensaklaran 2 ( A - C)

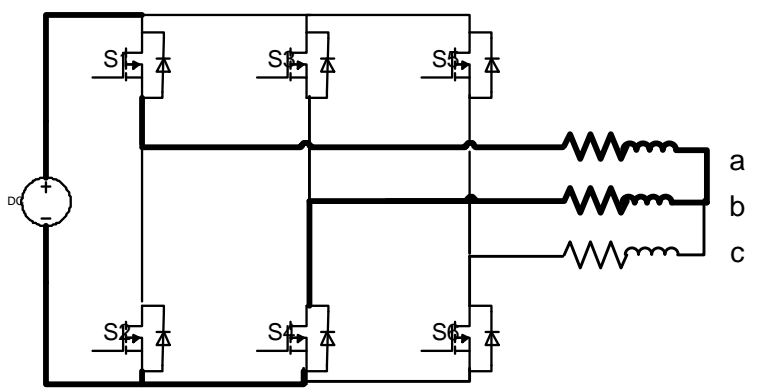

Gambar 6 mode operasi pensaklaran 3 ( A - B )

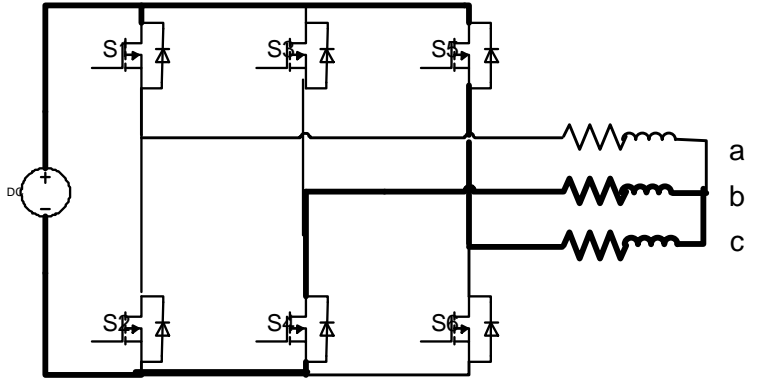

Gambar 7 mode operasi pensaklaran 4 ( C - B )

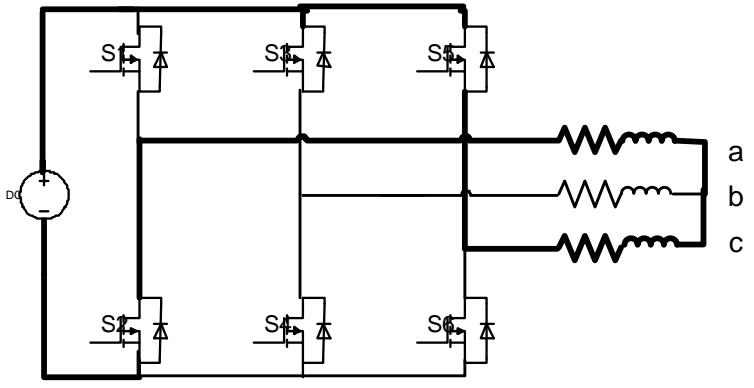

Gambar 8 mode operasi pensaklaran 5 ( C - A)

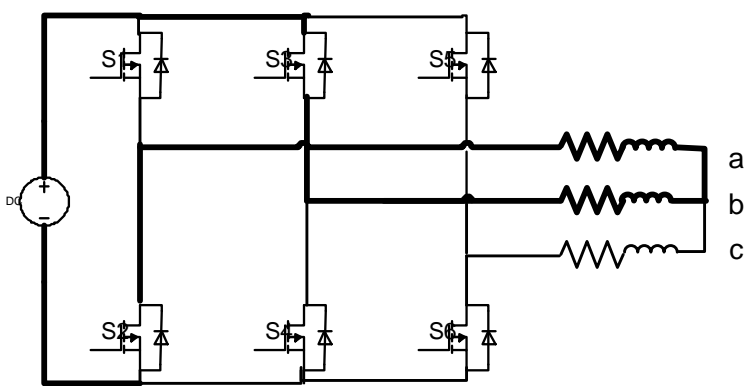

Gambar 9 mode operasi pensaklaran 6 ( B - A)

Dari operasi tersebut maka dihasilkan enam macam konfigurasi switching dari inverter tersebut secara berulang dengan rasio putaran $360^{\circ}$. Sistem pensaklaran dapat dijelaskan pada mode operasi tersebut.

\section{Hasil Pengujian}

Pada pengujian ini motor BLDC dijalankan pada kondisi motoring berbasis dsPIC30F4012. Dengan topologi Inverter Tiga Fasa sebagai rangkaian daya motor BLDC. Pembacaan pada posisi rotor dengan menggunakan tiga sensor hall effect untuk mendeteksi letak magnet pada rotor. berdasarkan dari hasil . Sistem kontrol terdiri dari sebuah driver yang didalamnya terdiri dari enam IC optocoupler TLP250 dan inverter 3 fasa menggunakan IGBT CPV Model CPV364M4F, juga sebuah catu daya yang terdiri dari komponen B1212 dan B1205 yang menghasilkan keluaran $12 \mathrm{~V}$ dan $5 \mathrm{~V}$. 
Pada implementasi ini juga menggunakan (Digital Signal Controller) DSC dsPIC30f4012 sebagai kendali driver pada inverter tiga fasa yang memiliki peran sebagai kontrol motor BLDC.

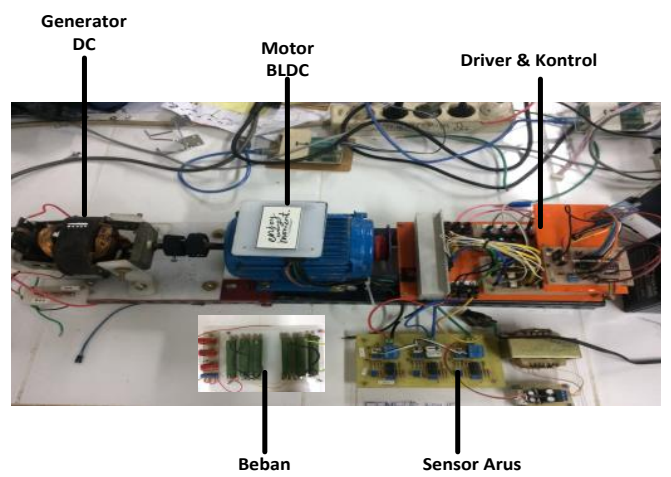

\section{Gambar 10 prototype motor brushless DC}

Setelah itu motor BLDC dijalankan dalam kondisi motoring, pembebanan direalisasikan dengan menggunakan generator DC yang diaplikasikan sebagai roda pada system penggerak mekanik yang dibebani dengan variable resistor dengan nilai variasi $15 \Omega, 30 \Omega$, dan $45 \Omega$. Di bawah ini akan ditampilkan hasil pengujian pembebanan pada motor brushless dc dalam kondisi motoring.

Di bawah ini akan disajikan hasil pengujian pada motor BLDC dengan variasi beban resistor $15 \Omega, 30 \Omega$ dan $45 \Omega$ dalam kondisi motoring. Dimana hasil yang ditampilkan berupa gelombang arus, tegangan, dan antar tegangan dengan oscilloscope.

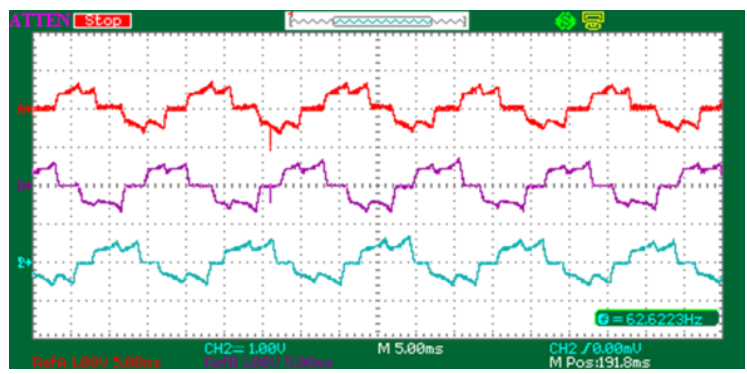

Gambar 11 hasil pengujian arus (la, Ib, Ic) keluaran dengan beban $15 \Omega$

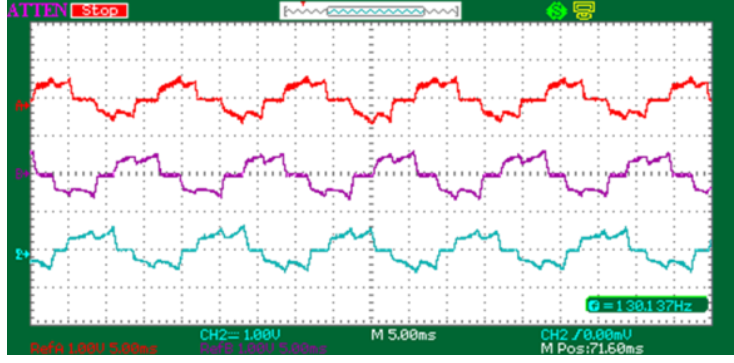

Gambar 12 hasil pengujian arus keluaran (la, lb, lc) dengan beban $30 \Omega$

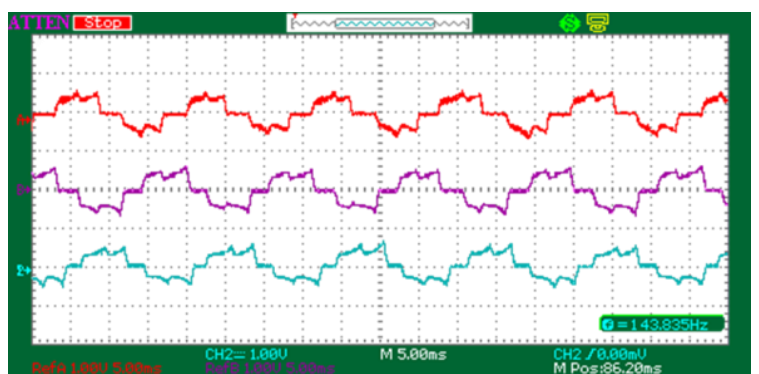

Gambar 13 hasil pengujian arus keluaran (la, lb, lc) dengan beban $45 \Omega$

Dari gambar 11, gambar 12 dan gambar 13 dapat dilihat bahwa perbandingan gelombang arus pada (la, Ib, Ic) dari beban $15 \Omega, 30 \Omega$ sampai $45 \Omega$ mengalami penurunan.

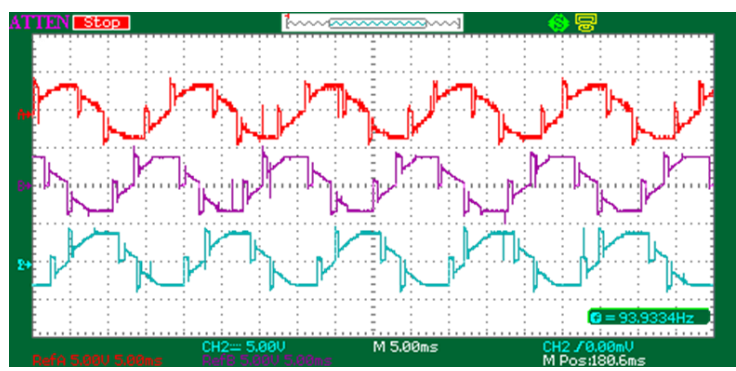

Gambar 14 hasil pengujian tegangan keluaran antar fasa (Vab. Vbc, Vca) dengan beban $15 \Omega$

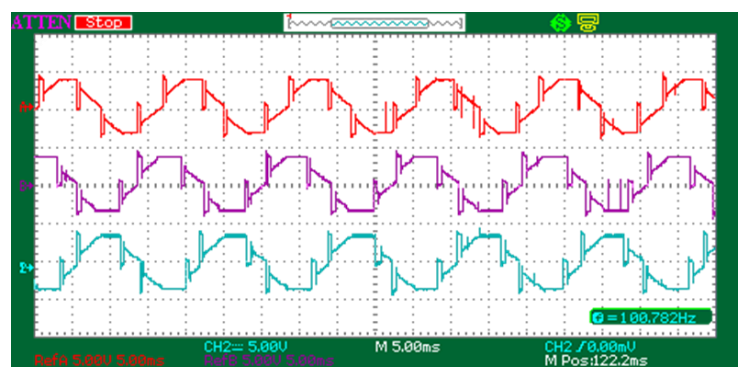

Gambar 15 hasil pengujian tegangan keluaran antar fasa (Vab, Vbc, Vca) dengan beban $30 \Omega$ 


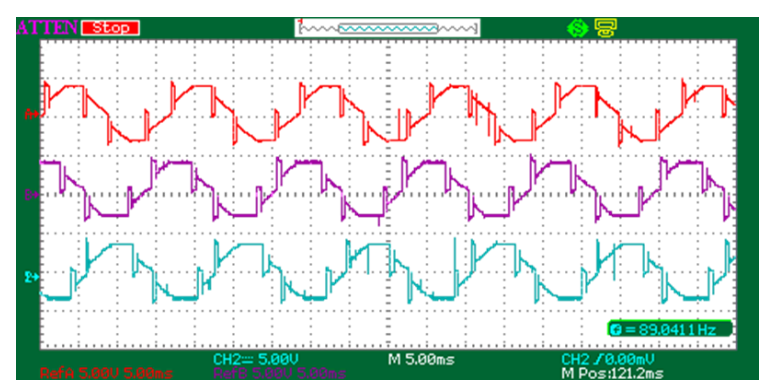

Gambar 16 hasil pengujian tegangan keluaran antar fasa (Vab, Vbc, Vca) dengan beban $45 \Omega$

Dari gambar 14, gambar 15 dan gambar 16 dapat dilihat bahwa perbandingan gelombang tegangan antar fasa (Vab, Vbc, Vca) dari variasi beban $15 \Omega, 30 \Omega$ dan $45 \Omega$ tidak mengalami perubahan.

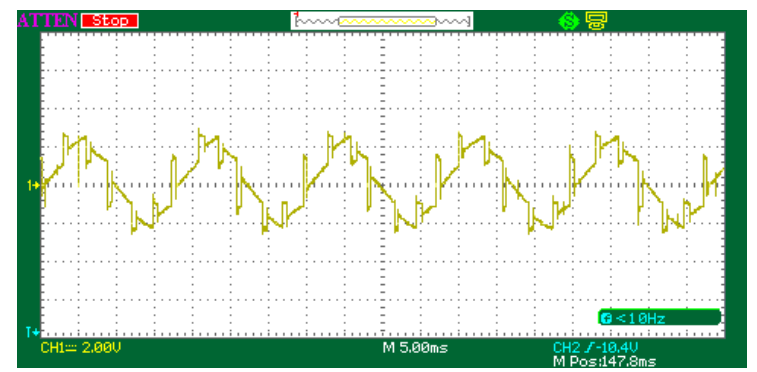

Gambar 17 hasil pengujian tegangan keluaran tiap fasa Van dengan beban $15 \Omega$

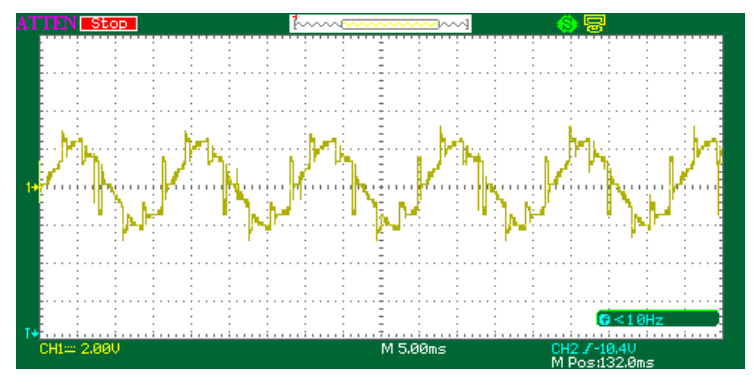

Gambar 18 hasil pengujian tegangan keluaran tiap fasa Van dengan beban $30 \Omega$

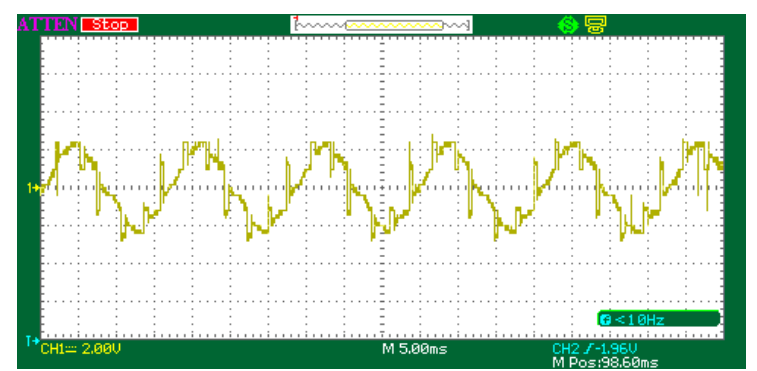

Gambar 19 hasil pengujian tegangan keluaran tiap fasa Van dengan beban $45 \Omega$
Dari gambar 17, gambar 18 dan gambar 19 dapat dilihat bahwa perbandingan sinyal tegangan tiap fasa Van dari variasi beban $15 \Omega, 30 \Omega$ dan $45 \Omega$ tidak mengalami perubahan.

Analisa yang telah dilakukan dengan kajian pembebanan motor BLDC, pembebanan direalisasikan dengan menggunakan generator DC yang diaplikasikan sebagai roda pada penggerak mekanik yang dibebani dengan variable resistor $15 \Omega$, 30 $\Omega$, dan $45 \Omega$. Setelah melaksanakan pengujian prototipe dan telah mendapatkan hasil dari pengujian, kemudian analisa dapat digunakan sebagai pendukung dari hasil yang telah diperoleh yaitu sebagai perbandingan pembebanan, hasil kecepatan diperoleh dari hasil pengukuran menggunakan alat ukur tachometer dan keluaran generator dc yang diperoleh. Ditampilkan pada tabel 1 dibawah ini.

Tabel 1 Ringkasan Hasil Pengujian Alat

\begin{tabular}{|c|c|c|c|}
\hline No & Beban & $\begin{array}{c}\text { Keluaran } \\
\text { Medan }\end{array}$ & $\begin{array}{c}\text { Kecepatan } \\
\text { (Rpm) }\end{array}$ \\
\hline 1 & $15 \Omega$ & $3,8 \mathrm{~V}$ & 380 \\
\hline 2 & $30 \Omega$ & $5,7 \mathrm{~V}$ & 567 \\
\hline 3 & $45 \Omega$ & $7,0 \mathrm{~V}$ & 867 \\
\hline
\end{tabular}

\section{Nomenkaltur}

$\mathrm{B}=$ Kerapatan medan magnet yang dihasilkan rotor (Tesla)

$\mathrm{N}=$ Banyaknya lilitan pada belitan stator perphasa

1 = Panjangnya batang rotor $(\mathrm{m})$

$\mathrm{R}=$ Jari-jari dalam motor $(\mathrm{m})$

$\omega=$ Kecepatan sudut putaran motor (rad) dimana $\omega=$ $\omega=2 \pi f$

$\mathrm{T}=$ Torka motor

$\mathrm{Krms}=$ Tegangan rata-rata konstan (Volt)

$\Phi$ = Besarnya fluks magnet (Tesla)

= Besarnya arus (ampere)

= Beda potensial / tegangan (Volt) 


\section{Kesimpulan}

Dalam penelitian ini dapat ditunjukan pengaruh variasi beban resistif, semakin besar beban maka semakin tinggi kecepatan motor BLDC dan arus menjadi kecil, jika semakin kecil beban maka kecepatan motor BLDC akan rendah dan arus menjadi lebih besar.

\section{Daftar Pustaka}

[1] Zhao, Jian., Yu, Yangwei. AN047 "Brushless DC Motor Fundamentals Application Note" 2011

[2] Brown, Ward. Microchip Technology Inc. AN857 "Brushless DC Motor Control Made Easy" 2012

[3] Jagat Jyoti Rath "Effective Speed Control in 3Phase BLDC Motor by Reaching Law based Sliding Mode Technique" International Journal of Computer Applications (0975 - 8887) Volume 43- No.16, April 2012

[4] Akash Varshney; Bharti Dwivedi "Perfomance Analysis of a BLDC drive under varying load" 2016 IEEE Internasional Conference

[5] Agung Dwi Yulianta, Sasongko Pramono Hadi \& Suharyanto "Pengendalian Kecepatan Motor Brushless DC (BLDC) menggunakan Metode Logika Fuzzy" Jurnal Sains, Teknologi dan Industri, Vol. 12, No. 2, Juni 2015

[6] Ahmad Fachrudin Istiananda, Ir. Rusdhianto Effendie A.K. M.T., dan Andri Ashfahani S.T., M.T., M.Sc. "Perancangan dan Implementasi Sistem Pengaturan Kecepatan Motor Arus Searah Tanpa Sikat Menggunakan Metode PIDRobust" Jurnal Teknik ITS Vol. 5, No. 2, (2016) ISSN: 2337-3539

[7] Tawfikur Rahman, S. M. A. Motakabber and M. I. Ibrahimy "Design of a Switching Mode Three Phase Inverter" 2016 International Conference on Computer \& Communication Engineering

[8] Akash Bhadani; Dhruvin Koladiya; Jaydip Devani; Prof. Archana Tahiliani "Modelling and Controlling of BLDC Motor" International Journal of Advance Engineering and Research Development Volume 3, Issue 3, March -2016

[9] Manali P.Chavhan; Sanjay M.Shinde "Modeling of Brushless DC Motor with Various Loading Conditions for Electric Vehicle Application" International Journal of Engineering Research and Development e-ISSN: 2278-067X, p-ISSN: 2278-800X, www.ijerd.com Volume 12, Issue 6 (June 2016)

[10] Y.B. Adyapaka Apatya ; Aries Subiantoro ; Feri Yusivar "Design and prototyping of 3phase BLDC motor" 2017 15th International Conference on Quality in Research (QiR) : International Symposium on Electrical and Computer Engineering 